\title{
A Trypanosoma cruzi Genome Tandem Repetitive Satellite DNA Sequence as a Molecular Marker for a LAMP Assay for Diagnosing Chagas' Disease
}

\author{
Diego Ordóñez $\mathbb{D},{ }^{1}$ Pedro Fernández-Soto $\mathbb{D}^{2},{ }^{2}$ Ana M. Fernández-Martín, ${ }^{2}$ \\ Beatriz Crego-Vicente $\mathbb{I D}^{2}$, Begoña Febrer-Sendra, ${ }^{2}$ Juan García-Bernalt Diego $\mathbb{D}^{\mathrm{D}}{ }^{2}$ \\ Belén Vicente, ${ }^{2}$ Julio López-Abán $\mathbb{D D}^{2}{ }^{2}$ Moncef Belhassen-García, ${ }^{2}$ Antonio Muro $\mathbb{D}^{2},{ }^{2}$ \\ and Manuel A. Patarroyo (iD ${ }^{3,4}$ \\ ${ }^{1}$ Animal Science Faculty, Universidad de Ciencias Aplicadas y Ambientales (U.D.C.A), 111166 Bogotá, Colombia \\ ${ }^{2}$ Infectious and Tropical Diseases Research Group (e-INTRO), Biomedical Research Institute of Salamanca, Research Centre for \\ Tropical Diseases at the University of Salamanca (IBSAL-CIETUS), Faculty of Pharmacy, University of Salamanca, \\ 37007 Salamanca, Spain \\ ${ }^{3}$ School of Medicine and Health Sciences, Universidad del Rosario, 112111 Bogotá, Colombia \\ ${ }^{4}$ Fundación Instituto de Inmunología de Colombia (FIDIC), 111321 Bogotá, Colombia
}

Correspondence should be addressed to Antonio Muro; ama@usal.es and Manuel A. Patarroyo; mapatarr.fidic@gmail.com

Received 5 December 2019; Accepted 17 January 2020; Published 24 February 2020

Guest Editor: Marcos Vinícius da Silva

Copyright @ 2020 Diego Ordóñez et al. This is an open access article distributed under the Creative Commons Attribution License, which permits unrestricted use, distribution, and reproduction in any medium, provided the original work is properly cited.

\begin{abstract}
Chagas' disease is a neglected tropical disease caused by Trypanosoma cruzi which is endemic throughout Latin America and is spread by worldwide migration. Diagnosis is currently limited to serological and molecular techniques having variations regarding their sensitivity and specificity. This work was aimed at developing a new sensitive, applicable, and cost-effective molecular diagnosis technique for loop-mediated isothermal amplification-based detection of T. cruzi (Tc-LAMP). The results led to determining a highly homologous satellite repeat region $(231 \mathrm{bp})$ among parasite strains as a molecular marker for diagnosing the disease. Tc-LAMP was performed correctly for detecting parasite DNA ( $5 \mathrm{fg}$ for the CL Brener strain and $50 \mathrm{fg}$ for the DM28, TcVI, and TcI strains). Assay results proved negative for DNA from 16 helminth species and 7 protozoa, including Leishmania spp. Tc-LAMP based on the highly repeated T. cruzi satellite region is thus proposed as an important alternative for diagnosing T. cruzi infection, overcoming other methods' limitations such as their analytic capability, speed, and requiring specialized equipment or highly trained personnel. Tc-LAMP could be easily adapted for point-of-care testing in areas having limited resources.
\end{abstract}

\section{Introduction}

American trypanosomiasis, or Chagas' disease, is a zoonotic disease, usually consisting of chronic parasitic infection caused by the kinetoplastid protozoan Trypanosoma cruzi. The World Health Organization (WHO) recognizes Chagas' disease as one of the 20 neglected tropical diseases (NTD) [1] and one of the 13 most NTD worldwide [2]. Chagas' disease was considered a strictly rural disease for many decades; however, socioeconomic changes, rural exodus, deforesta- tion, and urbanization have transformed the disease's epidemiological profile, making it an increasingly urban phenomenon and a major public health problem [3]. The disease can currently be found in 21 Latin American countries, and it has been estimated that at least 8 million people are infected worldwide. Migration has increased the disease's incidence, and it has been spread to other continents $[2,4]$.

Chagas' disease diagnosis depends on the phase in which a patient is found to be. Parasitemia is high during the acute phase and the congenital form, as well as in reactivations 
caused by immunosuppression during the chronic phase. The parasite can be detected by microscopy in peripheral blood by thin or thick smear with Giemsa staining [5]. Sensitivity can be increased by concentration techniques such as microhematocrite concentration or Strout (double centrifugation) methods [6]. Techniques like hemoculture or xenodiagnosis have already been abandoned [7]. The parasite can sometimes be detected in cerebrospinal liquid [8]. Direct parasitological methods usually prove negative in 30\%-60\% of patients during the disease's chronic phase (having minimum parasitemia). Diagnosis is thus serological during this phase, based on detecting anti-T. cruzi IgG antibodies.

Conventional serological techniques (indirect immunofluorescence (IFI), indirect hemagglutination (IHA), and multienzyme assays (ELISA)) use the complete parasite or antigen mixtures as an antigen. However, less conventional serological assays use purified and/or recombinant antigens and synthetic peptides. Such techniques are more sensitive than direct observation methods but involve problems regarding poor specificity associated with antigen differences between recombinant proteins from different parasite lineages [9]. As no available serological test has $100 \%$ sensitivity and specificity, the WHO defines the diagnosis of the disease during its chronic phase by positivity in two serological tests carried out using different methods. A third test must be performed in case of discrepancy between the forgoing two results to confirm or discard infection [8]. Discrepancies are often due to crossed reactions with other trypanosomatids, including Leishmania spp.

Detecting T. cruzi DNA in peripheral blood by polymerase chain reaction (PCR) has become increasingly more used during the last few years, and the Special Program for Research and Training in Tropical Diseases (TDR-WHO) supported a comparative international study of PCR for detecting T. cruzi [10]. Kinetoplastid DNA, satellite DNA repeated sequences, and ribosomal RNA genes are the most used amplification targets [11]. PCR has proven useful during acute-phase or chronic-phase reactivations due to its greater sensitivity compared to microscopy methods [12].

PCR use during the chronic phase is debatable because it gives a positive result in $40 \%-70 \%$ of patients who have previously been diagnosed by conventional serological methods, depending on the degree of parasitemia, sample volume, DNA purification, PCR target region, the study population's characteristics, and the great genetic variability between the parasite's discrete typing units (DTUs). Furthermore, a negative result does not exclude infection [13].

PCR has also been used for following up treatment efficacy so that a positive result at the end of treatment would indicate therapeutic failure [14]. Real-time (quantitative) PCR (qPCR) has been developed enabling parasite DNA detection and quantification from clinical samples, although having very variable levels regarding analytical reliability, specificity, and sensitivity [15-18] thereby hampering its standardization for use in routine clinical matters. Such methods are impracticable in endemic areas lacking resources since they are techniques requiring sophisticated equipment and qualified personnel and are expensive, making them unfeasible for use in field conditions in endemic areas having scarce resources.
Other sensitive and specific molecular techniques, which are simpler, faster, and cheaper than PCR and its variants, must thus be used in diagnosing Chagas' disease, such as nucleic acid isothermal amplification, i.e., loop-mediated isothermal amplification (LAMP). Such technique has recently been revealed as an alternative having great potential for diagnosis in endemic areas [19-22]. Progress has been described in recent years regarding new LAMP methodologies for Chagas' disease diagnosis [19]. However, such laboratory tools are still being developed and larger amounts of reagents and materials are needed which could increase the value of diagnosis in communities living in endemic areas, mainly in the third world. This work has thus been aimed at developing a new sensitive, applicable, and cost-effective LAMP assay for the molecular detection of T. cruzi.

\section{Methods}

2.1. DNA from T. cruzi and Other Parasites. A DNeasy Blood \& Tissue Kit (Qiagen, Hiden, Germany) was used for DNA extraction according to the manufacturer's instructions. The T. cruzi genomic DNA (gDNA) used in this study was obtained from CL Brener and Dm28 in vitro parasite strain culture maintained at the University of Granada's Biochemistry and Molecular Parasitology Department, Spain. A NanoDrop spectrophotometer (ND-1000) was used for measuring DNA from both strains which was subsequently diluted with ultrapure distilled water to final $0.5 \mathrm{ng} / \mu \mathrm{L}$ concentration. Serial 10 -fold dilutions $\left(1 \times 10^{-1}\right.$ to $1 \times 10^{-9} \mathrm{ng} / \mu \mathrm{L}$ ) from both $T$. cruzi DNA strains were then prepared and stored at $-20^{\circ} \mathrm{C}$ until use. The prepared DNA was used as a positive control in all LAMP reactions for evaluating the molecular assays' analytical sensitivity and specificity.

Twenty-three DNA samples taken from several other parasites available in our laboratory were also evaluated for determining LAMP assay specificity, including trematodes (Schistosoma mansoni, S. haematobium, Fasciola hepatica, Amphimerus sp., Dicrocoelium dendriticum, and Echinostoma caproni), cestodes (Hymenolepis diminuta, Echinococcus granulosus, Taenia saginata, and T. solium), nematodes (Anisakis simplex, Brugia pahangi, Loa, Mansonella perstans, Strongyloides venezuelensis, and Ascaris suum), and protozoa (Giardia intestinalis, Cryptosporidium parvum, Entamoeba histolytica, Plasmodium malariae, $P$. vivax, Leishmania infantum, and $L$. donovani). All DNA sample concentrations were measured with a NanoDrop spectrophotometer (ND-1000) and then diluted with ultrapure water to a final $0.5 \mathrm{ng} / \mu \mathrm{L}$ concentration and kept at $-20^{\circ} \mathrm{C}$ until use.

2.2. Designing LAMP Primers. The GenBank database (http:// www.ncbi.nlm.nih.gov/) was searched for identifying possible sequences which could have been proven useful for detecting T. cruzi DNA. Once the sequences for starting the analysis had been located, they were saved in FASTA text-based format for handling and edition using BioEdit Sequence Alignment Editor v7.2.5 [23]. It was then ascertained whether the sequences were also available in the 
TABLE 1: Main molecular targets for Trypanosoma cruzi DNA or RNA detection using PCR or RT-PCR. GenBank database accession numbers, the amplification method used (PCR for DNA or RT-PCR for RNA), base pair length, and references are indicated.

\begin{tabular}{|c|c|c|c|c|}
\hline Molecular target & Accession number & PCR/RT-PCR & Base pairs & Reference \\
\hline Nuclear satellite DNA & AY520036 & PCR & 195 & {$[24]$} \\
\hline Putative flagellar calcium-binding protein & Z54193 & PCR & 692 & [25] \\
\hline E13 repeated element & M74536 & PCR & 220 & [26] \\
\hline Kinetoplast minicircle variable region & AJ748042 & PCR & 330 & [27] \\
\hline 24S ribosomal RNA alpha-subunit & L14468 & RT-PCR & 100 & [28] \\
\hline Ribosomal intergenic spacer & M63895 & PCR & 1174 & [29] \\
\hline Transposon-like E22 repeated element & X95485 & PCR & 863 & [30] \\
\hline Subtelomeric conserved junction & AF100651 & PCR & 822 & [31] \\
\hline
\end{tabular}

TABLE 2: Similarity degree among TriTrypDB sequences.

\begin{tabular}{|c|c|c|c|c|}
\hline Target & Identity & $E$ value & Strain & Notes* \\
\hline Nuclear satellite DNA & $100 \%$ & $3 e-96$ & CL Brener/Tulahuen c12 & $\begin{array}{c}\text { Most abundant repetitive } \\
\text { sequence in T. cruzi } \\
\text { genome (up to } 9 \% \text { ) }\end{array}$ \\
\hline $\begin{array}{l}\text { Putative flagellar } \\
\text { calcium-binding protein }\end{array}$ & $99 \%$ & 0.0 & $\begin{array}{l}\text { CL Brener/JRc14/Tulahuen } \\
\text { c12/Dm28c/Marinkellei }\end{array}$ & $\begin{array}{c}\text { Sequence present in a } \\
\text { single copy. Low sensitivity }\end{array}$ \\
\hline E13 repeated element & $97 \%$ & 0.0 & $\begin{array}{c}\text { Tulahuen c12/CL } \\
\text { Brener/Dm28c/Esmeraldo }\end{array}$ & $\begin{array}{l}\text { Abundant repetitive sequence in } \\
\text { T. cruzi genome (up to 7\%) }\end{array}$ \\
\hline $\begin{array}{l}\text { Variable region of } \\
\text { kinetoplast minicircles }\end{array}$ & $100 \%$ & $6 e-172$ & $\begin{array}{l}\text { CL Brener/Tulahuen } \\
\text { c12/JRc14/Esmeraldo }\end{array}$ & $\begin{array}{c}\text { Variable region with low } \\
\text { specificity for LAMP } \\
\text { primer design }\end{array}$ \\
\hline $\begin{array}{l}24 \text { S ribosomal RNA } \\
\text { alpha-subunit }\end{array}$ & $97 \%$ & $2 e-44$ & $\begin{array}{l}\text { JRc14/SylvioX10/Dm28c/ } \\
\text { Tulahuen c12/Marinkellei/ } \\
\text { CL Brener/Esmeraldo }\end{array}$ & $\begin{array}{c}\text { Small size for LAMP } \\
\text { design and very conserved in } \\
\text { trypanosomatids }\end{array}$ \\
\hline $\begin{array}{l}\text { Ribosomal } \\
\text { intergenic spacer }\end{array}$ & $95 \%$ & $2 e-107$ & $\begin{array}{c}\text { JRc14/SylvioX10/Dm28c/ } \\
\text { Tulahuen c12/ } \\
\text { Esmeraldo/Brener }\end{array}$ & $\begin{array}{l}\text { Scarcely used for } \\
\text { T. cruzi detection }\end{array}$ \\
\hline $\begin{array}{l}\text { Transposon-like E22 } \\
\text { repeated element }\end{array}$ & $98 \%$ & 0.0 & $\begin{array}{c}\text { CL Brener/Tulahuen } \\
\text { c12/Esmeraldo/Dm28c }\end{array}$ & $\begin{array}{l}\text { Scarcely used for } \\
T . \text { cruzi detection }\end{array}$ \\
\hline $\begin{array}{l}\text { Subtelomeric } \\
\text { conserved junction }\end{array}$ & $96 \%$ & 0.0 & $\begin{array}{c}\text { Tulahuen c12/JRc14/ } \\
\text { CL Brener/Esmeraldo/Dm28c }\end{array}$ & $\begin{array}{l}\text { Scarcely used for } \\
T . \text { cruzi detection }\end{array}$ \\
\hline
\end{tabular}

${ }^{*}$ Consult the bibliography shown in Table 1 for more details about sequences.

TriTrypDB database (http://tritrypdb.org/tritrypdb/) which stores the complete T. cruzi genome. The sequences were then compared using the basic local alignment search tool (BLAST; https://blast.ncbi.nlm.nih.gov/Blast.cgi) for ascertaining the degree of homology and/or difference from the other specific trypanosomatid sequences available in the database. The resulting sequence was used for designing specific primers for $T$. cruzi amplification using LAMP Designer software (http://www.premierbiosoft .com/isothermal/lamp.html). Thermo Fisher Scientific synthesized the selected primers.

2.3. LAMP Assay for T. cruzi. LAMP reaction mixtures $(25.2 \mu \mathrm{L})$ each contained $40 \mathrm{pmol}$ FIP and BIP primers, 5 pmol F3 and B3 primers, 5 pmol LB and LF primers, $2.5 \mathrm{mM}$ dNTPs (Intron), $0.8 \mathrm{mM} \mathrm{MgSO}_{4}$ (New England Biolabs, UK), $1 \mathrm{M}$ betaine (Sigma, USA), $1 \mathrm{x}$ isothermal amplification buffer- $20 \mathrm{mM}$ Tris- $\mathrm{HCl}(\mathrm{pH} 8.8)$, and $8 \mathrm{U}$ Bst polymerase 2.0 WarmStart (New England Biolabs, UK) with $2 \mu \mathrm{L}$ (1 ng) of template DNA.
LAMP reactions were performed in $0.5 \mathrm{~mL}$ microcentrifuge tubes incubated in a heating block (K Dry Bath) at $63^{\circ} \mathrm{C}-65^{\circ} \mathrm{C}$ for $30 \mathrm{~min}, 45 \mathrm{~min}$, and $60 \mathrm{~min}$ to optimize the reaction; the temperature was then increased to $80^{\circ} \mathrm{C}$ for $5-10 \mathrm{~min}$ to deactivate the enzyme and stop the reaction. DNA contamination was prevented by using sterile tools at all times, each analysis step is performed in separate work areas, and reaction tube manipulation is minimized. Template DNA was replaced by ultrapure water as a negative control in each LAMP reaction. T. cruzi gDNA (10-fold serial dilutions as mentioned above) was also amplified for determining the LAMP assay's lower detection limit. LAMP assay specificity for only amplifying T. cruzi DNA was tested against 23 DNA samples from other parasites.

2.4. Detecting LAMP-T. cruzi Products. The LAMP amplification results were visualized by adding $2 \mu \mathrm{L}$ of $1: 10$ diluted SYBR Green I fluorescent dye (Invitrogen, Carlsbad, California, USA) to the reaction tubes. Green fluorescence was 
TABLE 3: Sequences and characteristics of the primers used.

\begin{tabular}{lccccc}
\hline Primer & Len & Tm & $3^{\prime} \mathrm{dG}$ & GC rate $(\%)$ & ${\text { Sequence }\left(5^{\prime} \text { to } 3^{\prime}\right)}^{\text {AACTATCCGCTGCTTGGA }}$ \\
\hline F3 & 18 & 60.8 & -1 & 50 & AAGAGCTCGCGAAATTCC \\
B3 & 18 & 60.2 & -0.4 & 50 & \\
FIP (F1c-F2) & 41 & & & & CCCACCATTCACAATCGGAAACCACTCGGCTGATCGTTTT \\
BIP (B1c-B2) & 41 & & & 50 & AGTCAGAGGCACTCTCTGTCAACCAAGCAGCGGATAGTTC \\
F2 & 19 & 60.3 & -0.7 & 55.6 & CACTCGGCTGATCGTTTT \\
F1c & 20 & 65.1 & 0.1 & 50 & CCCACCATTCACAATCGGAAAC \\
B2 & 18 & 65.1 & -0.9 & 50 & CCAAGCAGCGGATAGTTC \\
B1c & 22 & 72.5 & -0.9 & 50 & AGTCAGAGGCACTCTCTGTCAA \\
LF & 19 & 60.1 & 0.1 & 50 & TTGGACCACAACGTGTGAT \\
LB & 20 & 64.4 & -0.4 & & TTCACACACTGGACACCAAA \\
\hline
\end{tabular}

observed in positive LAMP reactions whilst keeping its original orange in negative reactions. LAMP products (3-5 $\mu \mathrm{L})$ were also monitored by electrophoresis in 1.5$2 \%$ agarose gel electrophoresis to corroborate colorimetric results. The gels were visualized under UV light and photographed using an ultraviolet Gel Documentation System (Uvitec, UK).

\section{Results}

3.1. Searching for and Selecting Molecular Targets for Designing LAMP Primers. Table 1 summarizes eight molecular targets found in literature and database analysis that have been traditionally used in PCR studies for T. cruzi DNA or RNA amplification.

The TriTrypDB database (http://tritrypdb.org) was used for a BLASTN local search and alignment analysis [32] to verify these target sequences in the T. cruzi genome; different degrees of homology were obtained when comparing them to different parasite strains (Table 2).

The satellite nuclear DNA 195bp sequence [24] was selected as a target for LAMP primer design following in silico analysis of the selected sequences and studying their main characteristics using TriTrypDB. This small $195 \mathrm{bp}$ sequence was included in a larger $938 \mathrm{bp}$ one (Tcruzi_ 30851; TriTrypDB), identical for many strains and highly repeated (up to 9\%) in the T. cruzi genome. Furthermore, PCR amplification of parasite DNA analytical sensitivity and specificity has been proven in a number of studies. This small $195 \mathrm{bp}$ sequence was manually extended to $231 \mathrm{bp}$ to guarantee producing LAMP primers regarding the minimum size supported by LAMP Designer software. A single set of six primers (F3, B3, FIP, BIP, LF, and LB) was produced. Table 3 shows the characteristics of the primers and nucleotide sequences.

3.2. Setting Up the LAMP Assay for T. cruzi: Tc-LAMP. The best amplification results and test reproducibility for CL Brener and Dm28 strains were obtained when the reaction mixtures were incubated at $65^{\circ} \mathrm{C}$ for $60 \mathrm{~min}$. Color changes were clearly observed when adding SYBR Green I to the post-

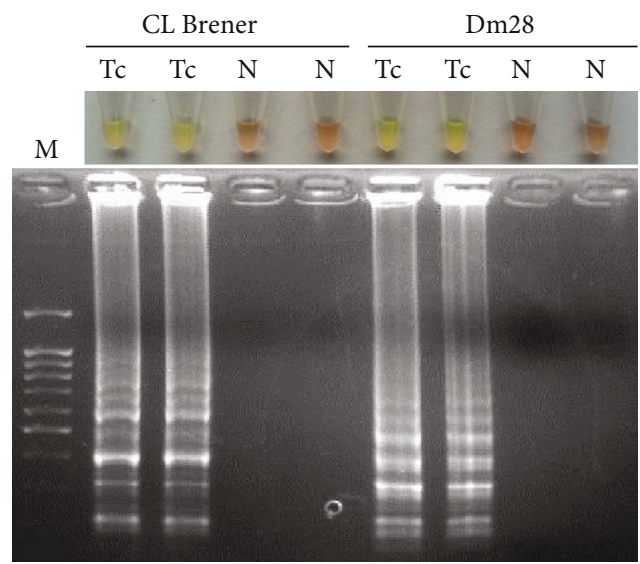

Figure 1: LAMP detection of Trypanosoma cruzi CL Brener and Dm28 strain DNA. Lanes Tc: T. cruzi DNA $(0.5 \mathrm{ng} / \mu \mathrm{L})$ from CL Brener and Dm28 strains; lanes $\mathrm{N}$ : negative controls (ultrapure water, no DNA). M: molecular weight marker (100 bp Plus Blue DNA Ladder).

amplification tubes, as was a ladder-like pattern in agarose gel electrophoresis (Figure 1).

The CL Brener strain DNA amplification detection limit was $5 \mathrm{fg}$ when evaluating Tc-LAMP reaction's analytical sensitivity, whereas the Dm28 strain detection limit was $50 \mathrm{fg}$ (Figure 2).

Tc-LAMP assay specificity was also tested using heterogeneous DNA samples as controls. Positive amplification was only observed using $T$. cruzi DNA (CL Brener or Dm28). DNA samples from other specimens tested were not amplified, thereby indicating that cross-reactions had not occurred. Colorimetric assay positive and negative results were clearly visualized and no ladders for bands were observed on agarose gels (Figure 3).

\section{Discussion}

Chagas' disease is an endemic protozoosis on the American continent, affecting its poorest communities, and has become a public health problem in many Latin American countries. Early diagnosis is essential for effective treatment to eliminate 


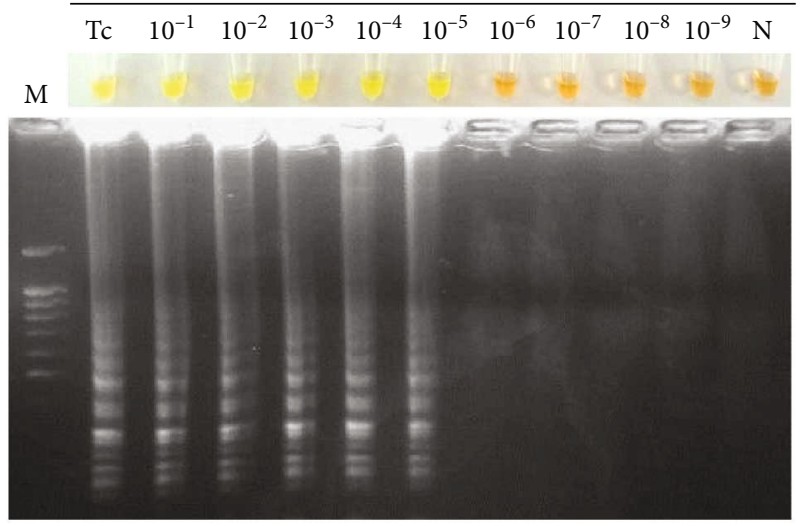

(a) CL Brener

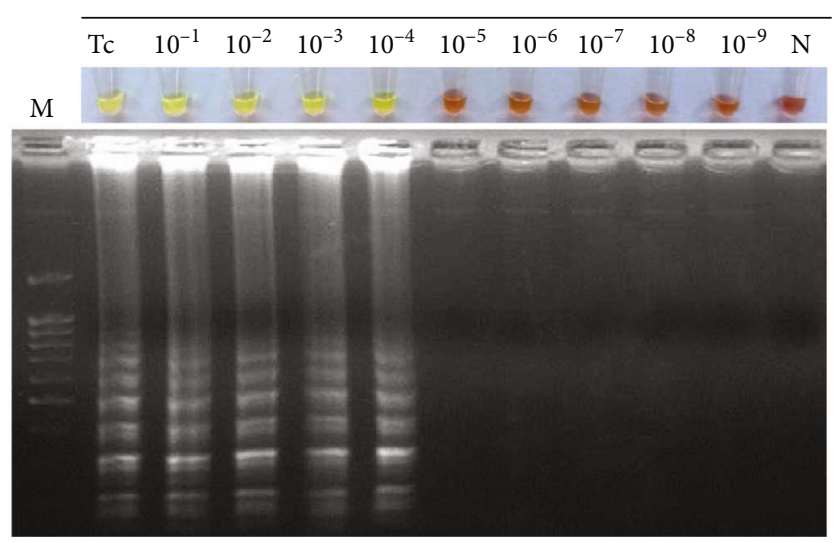

(b) $\operatorname{Dm} 28$

FIGURE 2: Assessment of Tc-LAMP analytical sensitivity for Trypanosoma cruzi using CL Brener and Dm28 strain gDNA serial dilutions. (a) Tc-LAMP sensitivity for the CL Brener strain. (b) Tc-LAMP sensitivity for the Dm28 strain. Lanes Tc: T. cruzi CL Brener and Dm28 strain gDNA $(0.5 \mathrm{ng} / \mu \mathrm{L})$; lanes $10^{-1}-10^{-9}: 10$-fold serial dilutions; lanes M: molecular weight marker (100 bp Plus Blue DNA Ladder).

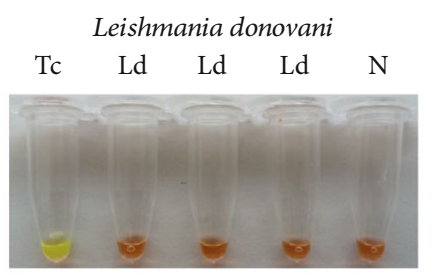

Leishmania infantum

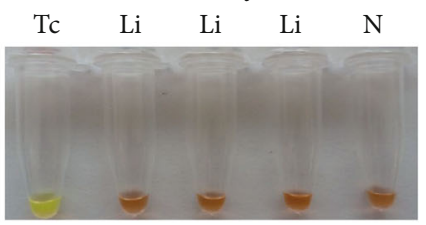

Protozoa

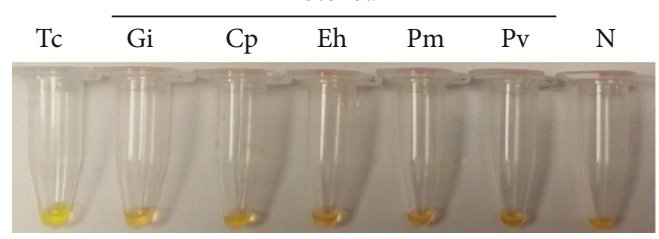

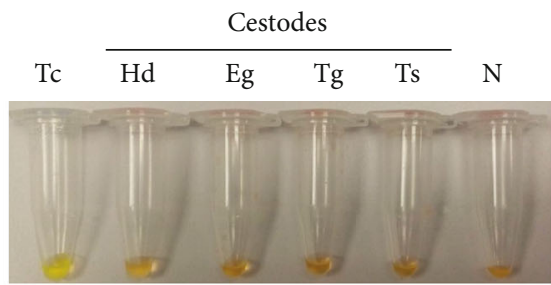
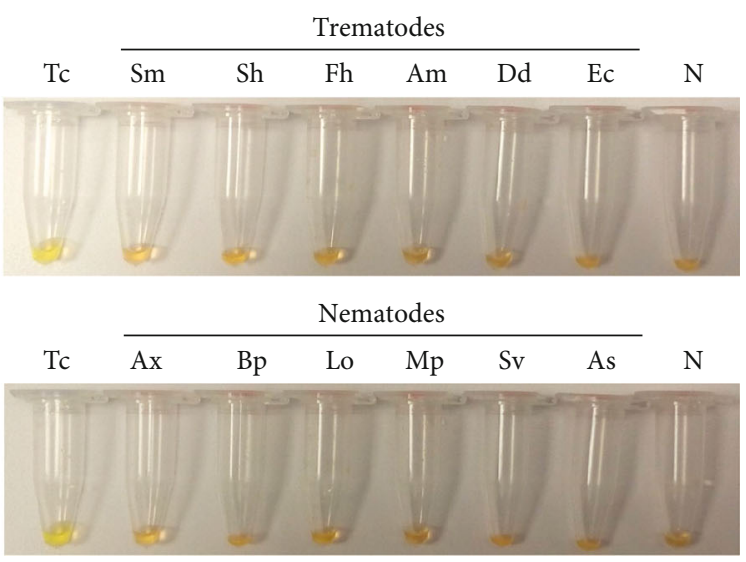

FiguRE 3: Tc-LAMP specificity: visual examination of LAMP products by adding SYBR Green I. Lanes Tc: T. cruzi CL Brener or Dm28 strain DNA $(0.5 \mathrm{ng} / \mu \mathrm{L})$; lanes N: negative controls (ultrapure water, no DNA). Trematode DNA in lanes Sm (Schistosoma mansoni), Sh (S. haematobium), Fh (Fasciola hepatica), Am (Amphimerus sp.), Dd (Dicrocoelium dendriticum), and Ec (Echinostoma caproni). Nematode DNA in lanes Ax (Anisakis simplex), Bp (Brugia pahangi), Lo (Loa loa), Mp (Mansonella perstans), Sv (Strongyloides venezuelensis), and As (Ascaris suum). Cestode DNA in lanes Hd (Hymenolepis diminuta), Eg (Echinococcus granulosus), Tg (Taenia saginata), and Ts (T. solium). Protozoan DNA in lanes Gi (Giardia intestinalis), Cp (Cryptosporidium parvum), Eh (Entamoeba histolytica), Pm (Plasmodium malariae), and $\operatorname{Pv}(P$ vivax). Leishmania donovani DNA in lane Ld (Leishmania donovani in triplicate). Leishmania infantum DNA in lane Li (Leishmania infantum in triplicate).

the parasite. However, both direct parasitological and serological methods have problems regarding their sensitivity and specificity. Molecular methods represent an alternative to be used for amplifying T. cruzi DNA. This work has described a LAMP technology-based molecular method (Tc-LAMP) developed for detecting the parasite.

The available databases (i.e., TriTrypDB and GenBank) were used for selecting eight sequences from different T. cruzi genome regions for designing useful primers for the LAMP assay; these sequences had been previously used for detecting T. cruzi DNA and that of its variants by PCR $[16,26,28]$. A small $195 \mathrm{bp}$ highly repeated (up to $9 \%$ ) nuclear DNA sequence in the T. cruzi genome [24] was selected as the potential molecular target for amplification following in silico analysis. This sequence is identical for many strains and has $100 \%$ identity with the CL Brener and Tulahuen c12 strains. This sequence's drawback lies in its small size for primer design, since LAMP Designer software requires 
a minimum $200-300 \mathrm{bp}$ for proper operation. The genome sequence included in a greater $938 \mathrm{bp}$ region was located in the T. cruzi genome to solve this problem. The selected sequence could thus be manually expanded to $231 \mathrm{bp}$, nearly the software's minimum size. The analysis gave a single set of 6 primers which included two loop primers. A repetitive nuclear DNA sequence amplifying a $231 \mathrm{bp}$ fragment was selected from these in silico studies and used for developing the LAMP technique for T. cruzi DNA amplification.

The reaction conditions were established in line with the previous work by our group for detecting DNA from other parasites $[33,34]$. CL Brener strain gDNA (a strain first used in sequencing the T. cruzi genome) [35] was amplified along with that from the Dm28 strain (a strain sequenced in 2014 and used in biochemical, immunological, gene expression, cell biology, and new drug development studies) [36]. Parasites involved in the domestic cycle belong to the CL Brener strain whilst circulating parasites in the sylvatic cycle belong to the Dm28 strain.

The Tc-LAMP detection limit was different for both strains tested: $5 \mathrm{fg}$ for CL Brener and $50 \mathrm{fg}$ for Dm28. Such differences regarding analytical sensitivity were probably due to variations among the DTUs distributed into six groups (TcI-TcVI) according to their molecular differences. There were also differences regarding the amount of their repetitive sequence content and genomic size, varying extensively among strains, even in the same DTU [37]. Thus, CL Brener strain genomic size (TcVI) was estimated to be $152.12 \mathrm{Mb}$, whilst Dm28 strain genomic size (TcI) was estimated to be $111.40 \mathrm{Mb}$. Satellite DNA was more abundant in the CL Brener strain (giving greater analytical sensitivity in our test) than in the Dm28 strain. The specificity studies involved a battery of available gDNA extracted from other parasites. The results were negative for the 16 helminth gDNA and the seven protozoan cDNA analyzed. It is worth highlighting the lack of gDNA detection in Leishmania species (Leishmania donovani and Leishmania infantum), although future studies would involve testing many more Leishmania species since coinfection with $T$. cruzi is a frequently occurring problem, especially in certain areas of the American continent. Moreover, trypanosomatid genomes share a high level of synteny $[38,39]$.

Only two LAMP assays were available for detecting $T$. cruzi gDNA when our LAMP assay was originally developed (both developed by the same research group) [40, 41]. A specific LAMP was developed for detecting $T$. cruzi, $T$. congolense, T. evansi, and T. brucei gambiense in one of the studies, using 5.8S rRNA gene internal transcribed spacer sequences (ITS2) for T. brucei gambiense, $18 \mathrm{~S}$ rRNA gene ITS2 for T. congolense and T. cruzi, and the VSG RoTat1.2 surface glycoprotein for $T$. evansi [40]. The T. cruzi detection limit was $1 \mathrm{fg}$ using Tulahuen strain DNA (TcVI human strain), such limit being greater than that detected in our assay. However, although specificity was evaluated in that study using gDNA from African trypanosomes and other protozoa, such as Toxoplasma, Theileria, and Babesia, specificity against Leishmania spp. species and $T$. rangeli mainly present on the American continent was not evaluated [42].

Significant advances in using LAMP for Chagas' disease diagnosis have currently been described [19]. However, more reagents and materials are needed for this which could thus increase the value of diagnosis for communities living in endemic areas, mainly in the third world.

\section{Conclusion}

Our study has described developing a specific LAMP method (Tc-LAMP) based on detecting a highly repeated and homologous satellite region among different strains for the sensitive and specific detection of T. cruzi DNA. The results led to proposing this marker/Tc-LAMP method as an accurate tool for Chagas' disease diagnosis, highlighting its advantages regarding speed, not needing specialized laboratory equipment or the need for highly trained personnel for running such tests.

\section{Data Availability}

The data used to support the findings of this study are available from the corresponding author upon request.

\section{Conflicts of Interest}

The authors declare that there is no conflict of interest regarding this publication.

\section{Authors' Contributions}

Diego Ordóñez and Pedro Fernández-Soto equally contributed as the first authors.

\section{Acknowledgments}

CL Brener and Dm28 DNA was kindly provided by Dr. Antonio Osuna (Universidad de Granada's Biochemistry and Molecular Parasitology Department, Granada, Spain). Leishmania infantum DNA was kindly provided by Dr. Pedro José Alcolea (Biological Research Center-CSIC, Madrid, Spain) and L. donovani DNA by Dr. Enrique Martínez (University Institute of Tropical Diseases, Tenerife, Canary Islands, Spain). We would also especially like to thank Jason Garry for translating and revising this manuscript. This work was funded by the Institute of Health Carlos III (ISCIII), Spain (http://www.isciii.es) (grants: RICET RD16/0027/0018 (AMA) and PI16/01784 (PFS)), cofunded by the European Union FEDER (Fondo Europeo de Desarrollo Regional) "Una manera de hacer Europa" programme, and also by the TCUE 2018-2020 Plan European Union and the Junta de Castilla y León. We would also like to acknowledge funding by the Universidad de Salamanca's Pre-PhD fellowship programme and cofinancing by the Banco Santander and Junta de Castilla y León Pre-PhD doctoral fellowship programme. 


\section{References}

[1] A. Moncayo and A. C. Silveira, "Current epidemiological trends for Chagas disease in Latin America and future challenges in epidemiology, surveillance and health policy," Memórias do Instituto Oswaldo Cruz, vol. 104, Suppl 1, pp. 17-30, 2009.

[2] P. J. Hotez, E. Dumonteil, L. Woc-Colburn et al., "Chagas disease: "the new HIV/AIDS of the Americas"," PLoS Neglected Tropical Diseases, vol. 6, no. 5, 2012.

[3] K. M. Bonney, "Chagas disease in the 21st century: a public health success or an emerging threat?" Parasite, vol. 21, p. 11, 2014.

[4] J. Gascon, C. Bern, and M. J. Pinazo, "Chagas disease in Spain, the United States and other non-endemic countries," Acta Tropica, vol. 115, no. 1-2, pp. 22-27, 2010.

[5] M. Flores-Chávez, I. de Fuentes, T. Gárate, and C. Cañavate, "Laboratory diagnosis of imported Chagas' disease," Enfermedades Infecciosas y Microbiología Clínica, vol. 25, pp. 29-37, 2007.

[6] R. G. Strout, "A method for concentrating hemoflagellates," The Journal of Parasitology, vol. 48, no. 1, p. 100, 1962.

[7] C. Bern, S. Kjos, M. J. Yabsley, and S. P. Montgomery, "Trypanosoma cruzi and Chagas' disease in the United States," Clinical Microbiology Reviews, vol. 24, no. 4, pp. 655-681, 2011.

[8] WHO, Control of Chagas disease: second report of the WHO expert committee, World Health Organization, Geneva, 2002.

[9] M. Flores-Chávez, I. Cruz, M. Rodríguez et al., "Comparison of conventional and non-conventional serological tests for the diagnosis of imported Chagas disease in Spain," Enfermedades Infecciosas y Microbiología Clínica, vol. 28, no. 5, pp. 284-293, 2010.

[10] A. G. Schijman, "Molecular diagnosis of Trypanosoma cruzi," Acta Tropica, vol. 184, pp. 59-66, 2018.

[11] A. G. Schijman, M. Bisio, L. Orellana et al., "International study to evaluate PCR methods for detection of Trypanosoma cruzi DNA in blood samples from Chagas disease patients," PLoS Neglected Tropical Diseases, vol. 5, no. 1, 2011.

[12] M. L. Gomes, L. M. Galvao, A. M. Macedo, S. D. Pena, and E. Chiari, "Chagas' disease diagnosis: comparative analysis of parasitologic, molecular, and serologic methods," The American Journal of Tropical Medicine and Hygiene, vol. 60, no. 2, pp. 205-210, 1999.

[13] C. Barnabé, T. De Meeûs, F. Noireau et al., “_Trypanosoma cruzi_discrete typing units (DTUs): Microsatellite loci and population genetics of DTUs $\mathrm{TcV}$ and $\mathrm{TcI}$ in Bolivia and Peru," Infection, Genetics and Evolution, vol. 11, no. 7, pp. 1752-1760, 2011.

[14] I. Molina, J. Gómez i Prat, F. Salvador et al., "Randomized trial of posaconazole and benznidazole for chronic Chagas' disease," The New England Journal of Medicine, vol. 370, no. 20, pp. 1899-1908, 2014.

[15] T. Duffy, M. Bisio, J. Altcheh et al., "Accurate real-time PCR strategy for monitoring bloodstream parasitic loads in Chagas disease patients," PLoS Neglected Tropical Diseases, vol. 3, no. 4, 2009.

[16] M. Piron, R. Fisa, N. Casamitjana et al., "Development of a real-time PCR assay for Trypanosoma cruzi detection in blood samples," Acta Tropica, vol. 103, no. 3, pp. 195-200, 2007.
[17] Y. Qvarnstrom, A. G. Schijman, V. Veron, C. Aznar, F. Steurer, and A. J. da Silva, "Sensitive and specific detection of Trypanosoma cruzi DNA in clinical specimens using a multi-target real-time PCR approach," PLoS Neglected Tropical Diseases, vol. 6 , no. 7, 2012.

[18] H. M. Valadares, J. R. Pimenta, J. M. de Freitas et al., "Genetic profiling of Trypanosoma cruzi directly in infected tissues using nested PCR of polymorphic microsatellites," International Journal for Parasitology, vol. 38, no. 7, pp. 839-850, 2008.

[19] S. A. Besuschio, M. Llano Murcia, A. F. Benatar et al., "Analytical sensitivity and specificity of a loop-mediated isothermal amplification (LAMP) kit prototype for detection of Trypanosoma cruzi DNA in human blood samples," PLoS Neglected Tropical Diseases, vol. 11, no. 7, 2017.

[20] M. Parida, S. Sannarangaiah, P. K. Dash, P. V. Rao, and K. Morita, "Loop mediated isothermal amplification (LAMP): a new generation of innovative gene amplification technique; perspectives in clinical diagnosis of infectious diseases," Reviews in Medical Virology, vol. 18, no. 6, pp. 407-421, 2008.

[21] D. H. Paris, M. Imwong, A. M. Faiz et al., "Loop-mediated isothermal PCR (LAMP) for the diagnosis of falciparum malaria," The American Journal of Tropical Medicine and Hygiene, vol. 77, no. 5, pp. 972-976, 2007.

[22] Y. P. Wong, S. Othman, Y. L. Lau, S. Radu, and H. Y. Chee, "Loop-mediated isothermal amplification (LAMP): a versatile technique for detection of micro-organisms," Journal of Applied Microbiology, vol. 124, no. 3, pp. 626-643, 2018.

[23] T. Hall, "BioEdit: a user-friendly biological sequence alignment editor and analysis program for windows 95/98/NT," Nucleic Acids Symposium Series, vol. 41, pp. 95-98, 1999.

[24] A. Gonzalez, E. Prediger, M. E. Huecas, N. Nogueira, and P. M. Lizardi, "Minichromosomal repetitive DNA in Trypanosoma cruzi: its use in a high-sensitivity parasite detection assay," Proceedings of the National Academy of Sciences of the United States of America, vol. 81, no. 11, pp. 3356-3360, 1984.

[25] A. M. Silber, J. Bua, B. M. Porcel, E. L. Segura, and A. M. Ruiz, "Trypanosoma cruzi: specific detection of parasites by PCR in infected humans and vectors using a set of primers (BP1/BP2) targeted to a nuclear DNA sequence," Experimental Parasitology, vol. 85, no. 3, pp. 225-232, 1997.

[26] J. M. Requena, A. Jimenez-Ruiz, M. Soto, M. C. Lopez, and C. Alonso, "Characterization of a highly repeated interspersed DNA sequence of Trypanosoma cruzi: its potential use in diagnosis and strain classification," Molecular and Biochemical Parasitology, vol. 51, no. 2, pp. 271-280, 1992.

[27] P. Wincker, C. Britto, J. B. Pereira, M. A. Cardoso, W. Oelemann, and C. M. Morel, "Use of a simplified polymerase chain reaction procedure to detect Trypanosoma cruzi in blood samples from chronic chagasic patients in a rural endemic area," The American Journal of Tropical Medicine and Hygiene, vol. 51, no. 6, pp. 771-777, 1994.

[28] R. P. Souto and B. Zingales, "Sensitive detection and strain classification of Trypanosoma cruzi by amplification of a ribosomal RNA sequence," Molecular and Biochemical Parasitology, vol. 62, no. 1, pp. 45-52, 1993.

[29] E. M. Novak, M. P. de Mello, H. B. Gomes et al., "Repetitive sequences in the ribosomal intergenic spacer of Trypanosoma cruzi," Molecular and Biochemical Parasitology, vol. 60, no. 2, pp. 273-280, 1993.

[30] J. Araya, M. I. Cano, H. B. M. Gomes et al., "Characterization of an interspersed repetitive DNA element in the genome 
ofTrypanosoma cruzi," Parasitology, vol. 115, no. 6, pp. 563570, 1997.

[31] M. A. Chiurillo, I. Cano, J. F. Da Silveira, and J. L. Ramirez, "Organization of telomeric and sub-telomeric regions of chromosomes from the protozoan parasite Trypanosoma cruzi," Molecular and Biochemical Parasitology, vol. 100, no. 2, pp. 173-183, 1999.

[32] S. F. Altschul, W. Gish, W. Miller, E. W. Myers, and D. J. Lipman, "Basic local alignment search tool," Journal of Molecular Biology, vol. 215, no. 3, pp. 403-410, 1990.

[33] P. Fernández-Soto, J. G. Arahuetes, A. S. Hernández, J. L. Abán, B. V. Santiago, and A. Muro, "A loop-mediated isothermal amplification (LAMP) assay for early detection of Schistosoma mansoni in stool samples: a diagnostic approach in a murine model," PLoS Neglected Tropical Diseases, vol. 8, no. 9, 2014.

[34] J. Gandasegui, P. Fernández-Soto, C. Carranza-Rodríguez et al., "The rapid-heat LAMPellet method: a potential diagnostic method for human urogenital schistosomiasis," PLoS Neglected Tropical Diseases, vol. 9, no. 7, 2015.

[35] N. M. El-Sayed, P. J. Myler, D. C. Bartholomeu et al., "The genome sequence of Trypanosoma cruzi, etiologic agent of Chagas disease," Science, vol. 309, no. 5733, pp. 409-415, 2005.

[36] E. C. Grisard, S. M. R. Teixeira, L. G. P. de Almeida et al., "Trypanosoma cruzi clone Dm28c draft genome sequence," Genome Announcements, vol. 2, no. 1, 2014.

[37] R. T. Souza, F. M. Lima, R. M. Barros et al., "Genome size, karyotype polymorphism and chromosomal evolution in Trypanosoma cruzi," PLoS One, vol. 6, no. 8, 2011.

[38] E. Ghedin, F. Bringaud, J. Peterson et al., "Gene synteny and evolution of genome architecture in trypanosomatids," Molecular and Biochemical Parasitology, vol. 134, no. 2, pp. 183-191, 2004.

[39] L. L. Naves, M. V. da Silva, E. F. Fajardo et al., "DNA content analysis allows discrimination between Trypanosoma cruzi and Trypanosoma rangeli," PLoS One, vol. 12, no. 12, 2017.

[40] O. M. Thekisoe, N. Kuboki, A. Nambota et al., "Species-specific loop-mediated isothermal amplification (LAMP) for diagnosis of trypanosomosis," Acta Tropica, vol. 102, no. 3, pp. 182-189, 2007.

[41] O. M. Thekisoe, C. V. Rodriguez, F. Rivas et al., "Detection of Trypanosoma cruzi and T. rangeli infections from Rhodnius pallescens bugs by loop-mediated isothermal amplification (LAMP)," The American Journal of Tropical Medicine and Hygiene, vol. 82, no. 5, pp. 855-860, 2010.

[42] K. A. M. Ferreira, E. F. Fajardo, R. P. Baptista et al., "Speciesspecific markers for the differential diagnosis of Trypanosoma cruzi and Trypanosoma rangeli and polymorphisms detection in Trypanosoma rangeli," Parasitology Research, vol. 113, no. 6, pp. 2199-2207, 2014. 